\title{
Homolateral ataxia and crural paresis: a syndrome of anterior cerebral artery territory infarction
}

\author{
Julien Bogousslavsky, Rosario Martin, Thierry Moulin
}

Department of

Neurology, Centre

Hospitalier

Universitaire Vaudois,

Lausanne, Switzerland

J Bogousslavsky

R Martin

Department of

Neurology, Hôpital

Jean-Minjoz,

Besançon, France

T Moulin

Correspondence to:

J Bogousslavsky, Department

of Neurology, Centre

of Neurology, Centre

Vaudois, $\mathrm{CH}-1011$

Lausanne, Switzerland.

Received 6 December 1991 and in revised form

17 March 1992.

Accepted 25 March 1992.

\begin{abstract}
Five patients with superficial anterior cerebral artery territory infarcts in the paracentral area are reported, who developed a hemiparesis which was predominant in the leg, and with homolateral ataxia in the arm. A similar neurological picture was not observed in 1736 patients who were admitted over an eight year period to a primary care stroke centre with their first stroke. Involvement of corticopontine fibres at their origin, together with damage to the lower limb motor strip or underlying white matter, appears to have been the cause of a clinical syndrome (homolateral ataxia and crural paresis) which has been ascribed to lacunar infarction.
\end{abstract}

(F Neurol Neurosurg Psychiatry 1992;55:1146-1149)
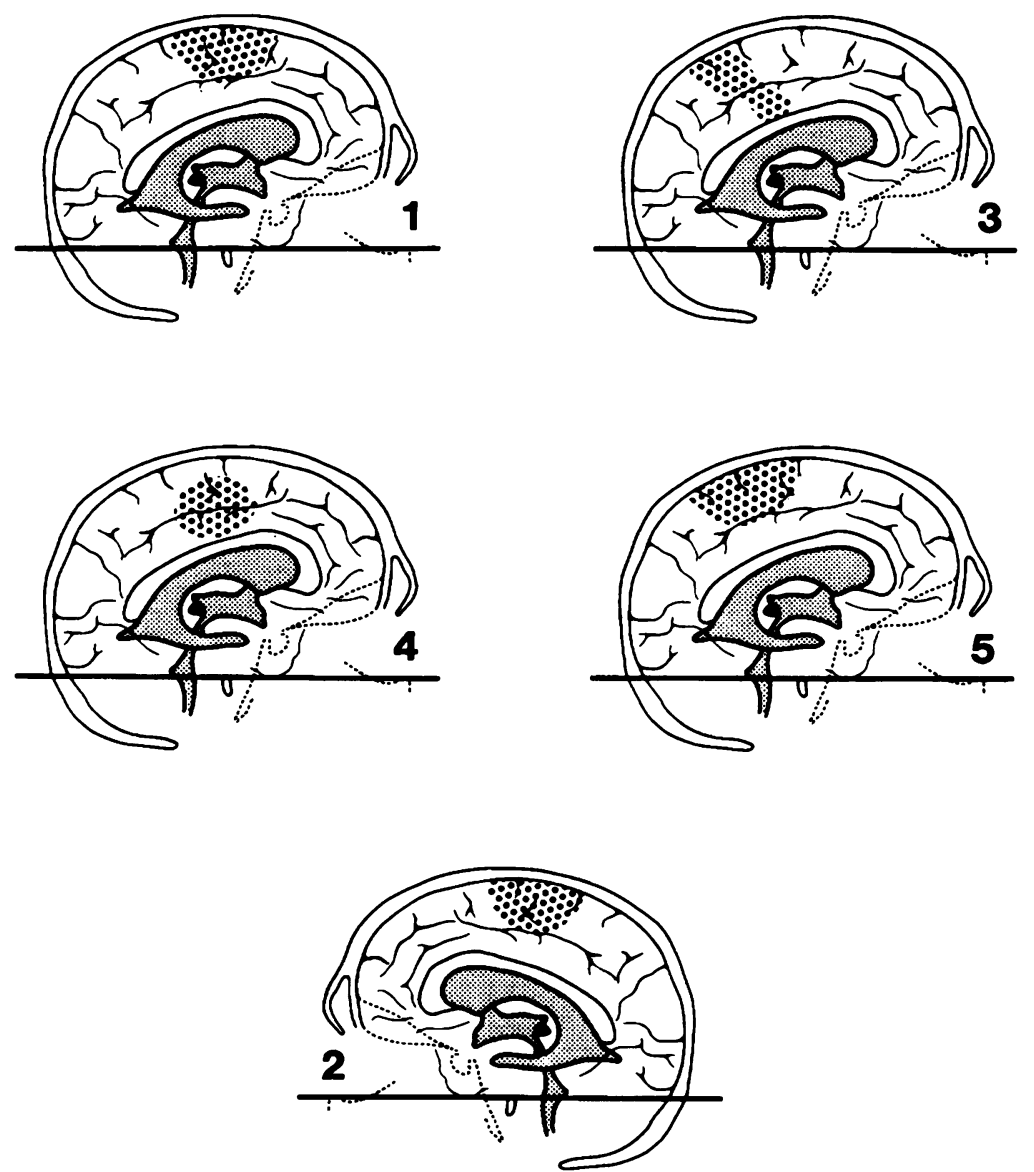

Figure 1 Topography of anterior cerebral artery infarcts in five patients. Sagittal reconstruction (After references ${ }^{1,3}$ ).

The neurological spectrum of anterior cerebral artery (ACA) infarcts includes a variety of motor, sensory, gaze and neuropsychological disturbances. ${ }^{12}$ We report five patients who developed homolateral ataxia and crural paresis, a syndrome usually ascribed to lacunar infarction. ${ }^{3-10}$

\section{Patients and methods}

Four of 1800 consecutive patients admitted to a primary care stroke centre over the past 8 years (Lausanne Stroke Registry ${ }^{11}$ ) showed acute crural paresis and homolateral ataxia of the arms. All had an ACA territory infarct on CT or MRI. All patients underwent the standard protocol of investigation of the Lausanne Stroke Registry; ${ }^{11}$ they were assessed neurologically by at least one staff neurologist. Neuropsychological examination included tests from a standard battery performed in our institution. ${ }^{12}$ A fifth patient from another stroke centre was included because he showed the same neurological and radiological picture. For clinical and topographical correlations, we reconstructed radiological findings in the sagittal plane using a method previously reported for assessing the topography of ACA territory infarcts. ${ }^{13}$

Four patients had a left-sided infarct and one had a right-sided infarct. The ACA territory infarct was partial in all five patients (figure 1). At the cortical level, it was posterior to the central sulcus in two patients ( 3 and 5) and centred around the central sulcus in three patients (1, 2 and 4). In both patients with posterior cortical involvement, the infarct extended into the subcortical white matter anteriorly. All patients had hemiparesis involving only or predominantly the leg, usually more proximal than distal, with homolateral extensor-plantar reflexes. Homolateral ataxia involved the arm in all five patients (in the absence of significant weakness) and also the leg in the patients in whom weakness did not preclude examination. Four patients showed no sensory dysfunction and only one (patient 3) had impairment of position sense in the legs. No patient had gaze disturbance, incontinence or grasp reflex.

\section{Case reports}

Patient 1 A 60 year old woman without known vascular risk factors developed acute clumsiness in the right arm and leg which gradually deteriorated over 24 hours. On examination, the day after onset, she was alert, oriented, and had normal speech. Cranial 
nerves were normal. She had a spastic paresis in the right leg, which was predomiant proximally. Strength was normal in both arms. Light touch, temperature, pain, position and vibratory sensation were all normal. Tendon reflexes were increased in the right arm and leg, and plantar responses were extensor. There was marked difficulty in performing the finger-tonose test on the right, with irregular accelerations producing oscillations. Rapid alternate movements were slowed and superimposed with gross saccades. Blood pressure was $130 / 80 \mathrm{~mm} \mathrm{Hg}$. CT three days after onset showed an area of decreased lucency with contrast enhancement in the left ACA territory over the central sulcus (see figure 1). Carotid angiography, transthoracic and transoesophageal echocardiography were normal. An extensive battery of blood and urine tests was normal. Six months after the stroke, only a slight crural paresis persisted, but a marked impairment was present in the right arm and leg, demonstrated by coordination tests.

Patient 2 A 49 year old woman with a history of hypertension, smoking and several previous episodes of transient ischaemic attacks involving the face and left arm and leg, developed acute weakness and clumsiness in the left leg with left arm incoordination. On examination 36 hours after onset, she was alert and oriented in time and place. She had a left hemiparesis with only slight involvement of the face and arm, but with lower limb hemiplegia. Light touch, temperature, pain, position and vibration sense were normal. On the left, she had difficulty in performing the finger-to-nose test, with irregular tremor and corrective movements. Tendon reflexes were increased on the left with an equivocal plantar response. Neuropsychological examination was normal. Blood pressure was $160 / 80 \mathrm{~mm} \mathrm{Hg}$. CT performed six days after admission showed an area of decreased lucency with contrast enhancement in the right ACA territory over the central sulcus (see figure 1). Extracranial and trancranial Doppler ultrasounds, two-dimensional echocardiography, and an extensive battery of blood and urine tests were normal. The patient improved rapidly and, one month after admission, her neurological examination was normal.

Patient 3 A 74 year old woman with a history of hypertension, hypercholesterolaemia and polymyalgia rheumatica, developed an acute right hemiparesis predominating in the leg. She had experienced an episode of heaviness and weakness involving the legs one month before admission, and an episode of right crural paresis two weeks later. On examination, she was alert and oriented, without neuropsychological dysfunction. She had a spastic hemiparesis involving the right leg. Light touch, temperature, pain and vibration sense were normal, but there was impairment of the position sense in her right leg. There was marked hypermetria and dysmetria with intention tremor in the right arm, with dysdiadochokinesia. Tendon reflexes were increased on the right and plantar responses were extensor. Blood pressure was $200 / 110 \mathrm{~mm} \mathrm{Hg}$. MRI performed on admission showed an area of increased signal on $\mathrm{T} 2$ weighted images in the left ACA territory posterior to the central sulcus (see figs 1 and 2). Doppler ultrasounds showed a $90 \%$ stenosis of both internal carotid arteries at their origin, with reversed ophthalmic flow. Six months after her stroke, a slight ataxia was present in the right arm and leg, without hemiparesis.

Patient 4 A 67 year old man with a history of smoking, alcoholism, atrial fibrillation and laryngectomy suddenly developed weakness and incoordination involving the right leg. On examination 12 hours later, he was alert and oriented, with normal speech. Cranial nerves were normal. He had a paresis of the right leg which was predominant proximally and with normal tone. Light touch, temperature, pain, position and vibration sense were normal. Tendon reflexes were increased on the right and plantar responses were extensor. Fingerto-nose and heel-to-knee tests were ataxic on the right. Alternate movements were slowed and saccadic on the right. The gait was ataxic.
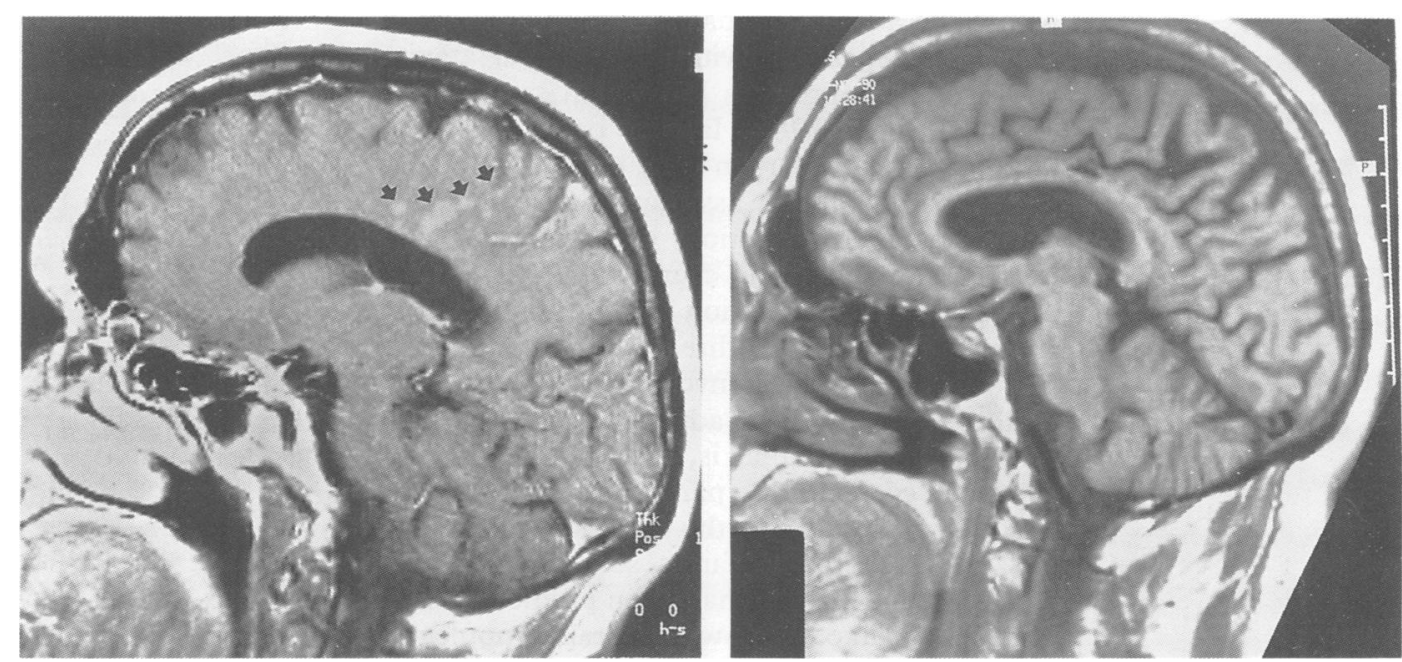

Figure 2 Patient 3. (left) Gadolinium-enhanced MRIT1 weighted scan two weeks after stroke showing an area of increased signal in the left ACA territory, posterior to the central sulcus. (right) MRI scan eight months later showing focal atrophy as a sequela. 
Blood pressure was $170 / 100 \mathrm{~mm} \mathrm{Hg}$. MRI three days after stroke showed an area of increased signal on T2 weighted images in the left ACA territory (see figure 1). Doppler ultrasounds suggested a left internal carotid artery occlusion. Two-dimensional echocardiography and a standard battery of blood and urine tests were normal. Six months after the stroke, his right leg was hypertonic but without paresis or incoordination.

Patient 5 An 81 year old woman without known vascular risk factors suddenly developed right-sided weakness. On examination 15 hours later, she was alert and oriented. She had a right hemparesis only slightly involving the face and arm but her leg was severely affected. Light touch, temperature, pain, position and vibration sense were normal. Tendon reflexes were normal but plantar responses were extensor on the right. There was marked ataxia on the right shown by the finger-to-nose test. She could not perform the heel-to-knee test on the right. Neuropsychological examination showed an impairment of verbal comprehension, agraphia and ideomotor apraxia. CT on admission was normal but 14 days later it showed a haemorrhagic infarction in the left ACA territory posterior to the central sulcus (see figure 1). The CT scan of this patient has been published before. ${ }^{14}$ One month after onset, a slight, right-sided paresis with ataxic gait persisted.

\section{Discussion}

The term homolateral ataxia and crural paresis was introduced in 1965 by Fisher and Cole ${ }^{15}$ to describe patients with hemiparesis predominating in the leg and ipsilateral hemiataxia predominating in the arm. These authors reported 14 patients, but details were given in only four; in one of them, necropsy showed multiple infarcts, including one in the internal capsule and one in the pons, contralateral to the signs. Since that report, homolateral ataxia and crural paresis has often been considered to be just a variant of the lacunar syndrome ataxic hemiparesis, and most recent clinical studies of lacunar syndromes have not distinguished it within the ataxic hemiparesis group. ${ }^{1016-19}$

Very few patients with homolateral ataxia and crural hemiparesis have been specifically reported since 1965 . In five patients ${ }^{5-8}$ the infarct was capsular on CT, but the patients either had marked associated disturbances (hemisensory dysfunction, dysarthria) or the homolateral ataxia and crural hemiparesis was only part of the evolution of an initially more severe hemiplegia. In three other patients, ${ }^{349}$ CT showed an infarct involving the upper part of the corona radiata adjacent to the lateral ventricle, an area that is, in fact, just underneath the cortex of the paracentral region, and which corresponds to the subcortical part of the ACA territory infarcts seen in our five patients. This location had been predicted over 70 years ago in patients with crural monoplegia with predominating cerebellar symptoms. ${ }^{20-22}$ In fact, it has been known for many decades that paracentral tumours may yield pseudocer- ebellar ataxia as the main clinical manifestation. ${ }^{23}$ More recently, Mizon and Rosa ${ }^{25}$ reported a patient with homolateral ataxia and crural hemiparesis associated with a parasagittal meningioma.

In ataxic hemiparesis, the ataxia has been tentatively explained by involvement either of the fibres connecting the ventrolateral nucleus of thalamus and precental cortex or of the corticopontine fibres. ${ }^{10}$ Hemiataxia or cerebellar signs from paracentral lesions have been attributed to involvement of the paracentral contingent of Arnold's frontopontine bundle or of Türck's parietopontine bundle. $^{23-25}$ So it is not surprising that in patients with an ACA territory infarct critically placed, involving both the corticopontine fibres at their origin and the lower limb motor strip (or underlying white matter), a picture of homolateral ataxia and crural hemiparesis may result. We did not observe this neurological picture in 1736 patients with their first stroke who were admitted during an eight year period, so we believe that ACA territory infarction may be the principal cause of this syndrome.

It is likely that this syndrome can also be produced by subcortical infarction involving the uppermost part of the corona radiata just below the paracentral cortex. ${ }^{349}$ We must emphasise that only one of our five patients (patient 5) showed neuropsychological disturbances pointing to a superficial lesion, whereas all the others only had the motor dysfunction. Our findings suggest that homolateral ataxia and crural hemparesis is not a lacunar syndrome, and that it should not be considered to be merely a variant of ataxic hemiparesis.

R Martin is on leave from the University of Alicante and is supported by a grant from the Council of Europe number 90062

1 Bogousslavsky J, Regli F. Anterior cerebral artery territory infarction in the Lausanne Stroke Registry: Clinical and infarction in the Lausanne Stroke Registry: Clinical
etiological patterns. Arch Neurol 1989;47:144-50.

2 Hung TP, Ryn SJ. Anterior cerebral artery syndromes. In: Vinken PJ, Bruyn GW, Klawans HL, eds. Handbook of clinical neurology. Vol. 53, Vascular diseases, part I (Toole JF, ed.), chapter 12, Amsterdam: Elsevier, 1989:339-52.

3 Perman GP, Racy A. Homolateral ataxia and crural paresis: Case report. Neurology 1980;30:1013-5.

4 Jabbari B, Gunderson C, McBurney JW. Improvement of ataxic hemiparesis with trihyxyphenidyl. Neurology 1983;33:1627-8.

5 Tredici G, Bogliun G, Sanguineti I. Capsular ataxic hemiparesis. Arch Neurol 1983;40:326.

6 Rosa A, Mizon JP, Betermiez P. Hémiparésie crurale avec ataxie homolatérale. A propos d'un cas avec étude
tomodensitométrique. Rev Oto Neuro Ophtalmol 1983;55:283-8.

7 Jacome DE. Homolateral ataxia and crural paresis. Arch Neurol 1983;40:659-60.

8 De Renzi E, Nichelle P, Christ G. Hemiataxia and crural hemiparesis following capsular infarct. $\mathcal{f}$ Neurol Neurosurg Psychiatry 1983;46:561-3.

9 Rosa A, Mizon JP. Hémiparésie crurale avec ataxie ipsilatérale. Rev Neurol 1984;140:515-6.

10 Orgogozo JM, Bogousslavsky J. Lacunar syndromes. In: Vinken PJ, Bruyn GW, Klawans HL, eds. Handbook of clinical neurology, vol 54, Vascular diseases, (Toole JF, ed.) 1989;235-69.

11 Bogousslavsky J, Van Melle G, Regli F, for the Lausanne Stroke Group. The Lausanne Stroke Registry: Analysis of 1000 consecutive patients with first stroke. Stroke 1988;19:1983-92.

12 Assal G. Batterie des examens neuropsychologiques du CHUV. Centre Hospitalier Universitaire Vaudois, Lausanne, 1985. 
13 Bogousslavsky J, Regli F. Infarctus du territoire de l'artère cérébrale antérieure gauche. I. Corrélations clinicotomodensitométriques. Rev Neurol 1987;143:21-31.

14 Bogousslavsky J. Lettre à l'éditeur. Rev Neurol 1986;142:796.

15 Fisher CM, Cole M. Homolateral ataxia and crural paresis: A vascular syndrome. I Neurol Neurosurg Psychiatry 1965;28:48-55.

16 Norrving B, Cronqvist S. Clinical and radiologic features of lacunar versus nonlacunar minor stroke. Stroke 1989;20:59-64.

17 Arboix A, Marti-Vilatta JL, Garcia JH. Clinical study of 227 patients with lacunar infarcts. Stroke 1990;21:842-7.

18 Hommel M, Besson G, Le Bas JF, et al. Prospective study of lacunar infarction using MRI. Stroke 1990;21:546-54.

19 Chamorro A, Sacco RL, Mohr JP, et al. Clinical-CT correlations of lacunar infarction in the stroke data bank. Correlations of lacunar inf

20 Gerstmann J. Zur Kenntnis der Störungen des Körper-
gleich-Gewichtes nach Schubverletztung des Stirnhirns. Monatschr Psychiat Neurol 1916;40:354-77.

21 Claude $\mathrm{H}$, Lhermitte J. Les paraplégies cérébellospasmodiques et ataxo-cérébello-spasmodiques consécutives aux diques et ataxo-cerébello-spasmodiques consecutives aux lésions bilatérales des lobules paracentraux par projectile
de guerre. Bull Soc Méd Hôp Paris 1916;40:796-804.

22 Nicolesco J, Cretu V, Demetresco L. Syndrome de l'artère cérébrale antérieure. Monoplégie crurale droite avec symptomatolgie cérébelleuse prépondérante. Bull Soc Med Hop Bucarest 1920;10:247-50.

23 Foix C, Thévenard A. Symptômes pseudo-cérébelleux d'origine cérébrale, tubercule de la région paracentrale postérieure. Rev Neurol 1922;1:1502-4.

24 Alajouanine T, Lemaire A. Tumeur de la région paracentrale postérieure avec symptômes pseudo-cérébelleux. Rev Neurol 1925;1:71-5.

25 Mizon JP, Rosa A. Hémiparésie à prédominance crurale et ataxie ipsilatérale par méningiome de la faux du cerveau. Rev Neurol 1986;142:68-9.

\section{Death of Wegener}

The sad death of Friederich Wegener in $1990^{1}$ may remind neurologists that the nervous system is affected in $48 \%$ of patients ${ }^{2}$ suffering the illness which bears his name. Wegener studied medicine in Munich and Kiel. In 1933 his first post-mortem was of a patient with granulomatous vasculitis. He presented this case with two other cases from Chemnitz and Breslau to the German Society of Pathology at Breslau in 1936. Aschoff had noted the disease was different from periarteritis nodosa. He published his observations in his classic paper " On a peculiar rhinogenic granulomatosis with particular involvement of the arterial system and the kidney".

He settled in Lübeck working as a lecturer in Pathology and fulfilling many invitations to lecture on the arteritides. Lübeck bestowed on him the "Doctor Medicinae Honoris Causae" on his retirement. He was pleased with the advent of effective therapy with cyclophosphamide and prednisolone; and with the serological aid to diagnosis afforded by the demonstration of granular fluorescent antinuclear cytoplasmic antibody in significant titre.

Early in 1990 he lectured to the International European meeting on Wegener's Granulomatosis and Related Vasculitic Syndromes in Zweibrücken. He died aged 83 on 9 July 1990.

JMS PEARCE

1 Wegener Friederich. Obituary (by Harald Lehmann). Lancet 1990;336:738.

2 Cohen Tervaert JW, Huitema MG, Hene RJ, et al. Prevention of relapses of Wegener's granulomatosis by treatment tion of relapses ofWegener's granulomatosis by treatment based on antineutrophil
cet 1990;336:709-11

3 Wegener F. Uber eine eigenartige rhinogene Granulomatose mit besonderer Beteiligung des Arteriensystems und der Nieren. Beitr path Anat 1939;102:36. 